\title{
The Relation between Personal Digital Archiving and Personal Information Management
}

\author{
Mingxi Yan ${ }^{1, a}$, Tai Sun ${ }^{2, b}$, Chang Zhao ${ }^{3, c}$ \\ ${ }^{1}$ Information school, The University of Sheffield, Western Bank, Sheffield, S10 2TN, UK \\ ${ }^{2}$ Purchasing department, Qingdao Baishiyou Composite Material Manufacturing Co., Ltd. , \\ Qingdao, China \\ ${ }^{3}$ Qingdao Jiaxin Finance and taxation agency Limited, Qingdao, China

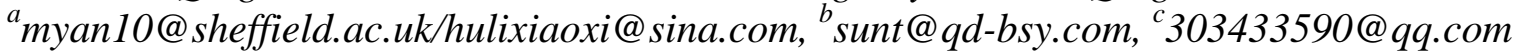

Keywords: personal digital archiving, personal information management

\begin{abstract}
This paper aims to discuss the relation between personal information management and personal digital archiving. This essay compares the understandings of PIM and PDA from different scholars in order to discuss the relation between them. In the first two parts, the concepts, main views and challenges are introduced. The second part is used to comparing the difference and similar and discuss the relation.
\end{abstract}

\section{Introduction}

Personal computers, tablet computer, smart phones and Internet are increasing popular. Because electronic products are not used for a long time and the most of users are young people, how to manage digital information resources has not attracted enough attention. A large number of personal information is scattered and valuable information cannot be effectively utilized and shared. In China, most literature on personal digital archiving management and personal information management reference the data from western countries. With the increase of personal information quantity, type and format, personal information management is becoming increasing difficult. That is to say, these have great improvement space. Therefore, this topic interests me and it is significant.

\section{Personal Information Management}

Jones (2008) defines personal information management (PIM) is a process which is used to capture, store, organize and retrieve individual information to assist life tasks. Gurrin, Albatal, Joho, and Ishii (2014) defines PIM as phenomenon which people record their daily lives and detail. Jones (2007) thinks organization and maintenance of personal information collections (PICs) is an essential part of PIM. This information items includes paper documents, electronic documents, handwritten notes, etc. In his report 2004, he also points whether and how to keep this information is an emphasis in PIM. From personal information management workshop (2016), its main theme includes 1. Managing personal information (PI) for longer periods of time. 2. Managing for later life. 3. Managing for legacy.

Personal information management should consider about people’s memory. Based on Elsweiler, 
Ruthven and Jones (2007), in personal information management, information which has features that people can recall will be tried to be obtained.

Jones proposes some short comings of PIM in 2004. Firstly, PIM is always inadvertently which will cause information fragmentation. This is to say, information is reserved in many places. It increases the cost of PIM and the difficulty of finding correct information. Secondly, according to theory of signal detectability (TSD), there are two kinds of errors: keeping useless information and deciding not to keep useful information. The most of problems of PIM are about whether and how to keep information. Reserved wrong information or reading useless information will decrease the efficiency if PIM. Lansdale (1988) provides other views which show short comings' of PIM can be psychological issues which based on the processes of recall, recognition and categorization. Some psychological issues are because users think they are inefficient. Jones also gives two tools to solve problems in his report in 2004. Firstly is supporting and enabling technologies to reduce keeping incorrect information or missing correct information. Secondly, developing strategies and tools, e.g.: PIM program. The whole organization will benefit from person information management.

\section{Personal Digital Archiving}

Personal digital archiving is a part of digital files and it can be created by anyone. Comparing with public records collections, personal records/manuscript collections is private (Amber 2010). In the view from Redwine (2015), personal digital archives include all possessions that were created by individual. For example, digital photographs, texts and emails. It may be no longer held by creators. Personal digital archives are usually created casually or inadvertently. Personal digital archives are significant and worth preserving because they record peoples' lives. Four main attributes, challenges and tasks are associated about personal digital archiving: are identified by Marshall (2007), digital stewardship/curatorial, effort; distributed storage; long term access, and value.

How to save digital files is a serious problem. Redwine (2015) points that individual lives matter will cause personal digital archives matter. And there are more reasons will cause the missing of personal digital archiving, for example: ageing hardware and software, lack of secure storage, natural and manmade disasters, etc.

The understanding of the risk of people's digital archives is a topic worthy of study. From the report which is written by Sinn, Syn and Kim (2011), their participants are aware that the content in e-mail and blogs may lose and it is hard to backup content because most e-mail and blog services do not provide backups. However, in the report from Becker and Nogues (2012), the most of 110 writers are not aware of their personal digital archiving needing to be concerned. Their digital archiving is poorly managed, highly distributed and unsystematically labelled files.

Marshall (2007) thinks some archival communities which have theories "provides traction on a set of slightly different issues to personal digital archiving" limits the usefulness of archival literature because personal digital archiving is unique. She also points the most of archival literature about personal archiving talked about management and cares which lacked the individual focus.

\section{Relation between Personal Digital Archiving and Personal Information Management}

From the above point of view, both personal digital archiving and personal information management focus on individual, but personal digital archiving only includes digital data. Jones (2007) thinks the lots of studies which relate personal information management focus on the use of email, Web or specific features (e.g.: bookmarks or history information) and the retrieval of documents in paper and electronic. Personal digital archiving is a personal information management concern (Marshall, 2007). Comparing with personal digital archiving, personal information 
management includes more content, for example: handwritten notes. Sun \& Belkin published a report about in 2016 which talks about diabetes patients' long term personal information management. Therefore, personal information management is much more complicated than personal archives management. Overall, personal digital archiving is a part of personal information management. In personal information management workshop (2016), personal digital archiving is related part.

As a kind of digital archiving, personal digital archiving has lots of advantages than traditional information management, e.g.: Large capacity, saving voice, easy to share, easy to change. However, it also faces many challenges. All of challenges that personal digital archiving faces also causes problems in personal information management, for example, whether and how to keep this information. Cushing (2010) thinks Personal digital archiving is a long term personal information issue. From the view of preservation, personal digital archiving pays more attention to individual lives matter. Compared with other archives, digital archives are harder to be obtained after people die. Marshall (2007) thinks personal digital archiving magnified additional problems of managing personal information for a long period of time. However, some issues which personal information faces are not magnified in personal digital archiving, e.g. how to organize and restore documents in paper. Furthermore, because of the rapidly development of technology, personal digital archiving brings lots of new questions. Sandusky (2017) thinks archivists faces big challenge because of rapid changes and a wide variety of born-digital formats in record. Traditional pencil and paper practices are not entirely suitable for new technology. He thinks even though Digital preservation systems (DPS) and digital asset management systems (DAMS) are increasingly common, these ways of dealing with digital are managed by technologists rather than archivists. Archival management systems lack integration with the DAMS/DPS. This is to say, personal digital archiving gives more develop space. Cushing (2010) thinks the combination of archival and the PIM will give more solutions then facing personal digital archiving challenges.

Both of personal information management and personal digital archiving need to consider about information behaviour. For example, the recall of them are influenced by memory. Marshall (2007) thinks the collection of personal digital archiving should be linked with personal information management habits. And the archival literatures which are written by the archival community lack individual focus.

Personal information management can be converted to personal digital archives to some extent. For example, Parry (2007) in his report talked about some information processing technology which is used to storage, retrieval, and indexing document in Museum, for example, microforms, electronic mail, Computer-aided mapping ,etc. As corollaries, personal information can be converted into personal digital archives by using technologies, e.g.: scanning. And in the future, more and more files will be turned into electronic files.

\section{Conclusion}

Some points personal digital archiving belongs to personal information management. It has some advantages, for example, more capacity, etc. It expands some of personal information management issues, for example, how to preserve the archiving. Some points the solutions of personal digital archiving can refer to personal information management and archival management. Being an important new part of personal information management, personal digital archiving also gives more development space for personal information management. Personal information management is more complicated than personal archives management. It includes more content, for example, paper documents. Different studies have different views on people's attitude towards information preservation. Personal information management is related to many other disciplines, such as 
computer science, archives management and psychology. Information fragmentation is unavoidable in the two management modes. Because of the technology, increasing quantity of documents are transferred to digital documents. When considering about personal information issues and personal digital archiving issues, personal information behaviours should to be concerned.

\section{References}

[1] Amber L. Cushing, (2010) "Highlighting the archives perspective in the personal digital archiving discussion", Library Hi Tech, Vol. 28 Issue: 2, pp.301-312,

[2] Becker D. and Nogues C. (2012), Saving-over, Over-saving, and the future Mess of Writer's digital Archives: A survey Report on the Personal Digital Archiving Practices of Emerging writers, Society of American Archivists, pp. 482-513

[3] Cushing, A. L. (2010). Highlighting the archives perspective in the personal digital archiving discussion. Library Hi Tech, 28(2), pp. 301-312.

[4] Elsweiler, D., Ruthven I.\& Jones C. (2007), Towards Memory Supporting Personal Information Management Tools, Department of Computer and Information Sciences, University of Strathclyde

[5] Gurrin, C., Albatal, R., Joho, H., \& Ishii, K. (2014). A privacy by design approach to lifelogging. pages 49

[6] Jones, W. (2004), Finders, keepers? The present and future perfect in support if personal information management. Retrieved on $29^{\text {th }}$ April 2018, from http://www.ojphi.org/ojs/index.php/fm/article/view/1123/1043

[7] Jones W. (2008) Keeping Found Things Found: The Study and Practice of Personal Information Management: The Study and Practice of Personal Information Management. Morgan Kaufmann Publishers Inc., San Francisco, CA, USA

[8] Lansdale, M. (1988). The psychology of personal information management. Applied Ergonomics, 19(1), 55-66.

[9] Marshall, C.C. (2007), "How people manage information over a lifetime", in Jones, W. and Teevan, J. (Eds), Personal Information Management, University of Washington Press, Seattle, WA, pp. 57-75.

[10] Marshall, C.C. (2007). Personal information management. How people manage information over a lifetime. In W. Jones \& J. Teevan (Eds.), Seattle, WA: University of Washington Press. pp. 57-75

[11] Parry, R. (2007). Recoding the Museum: Digital Heritage and the Technologies of Change. London: Routledge

[12] Personal information management workshop (2016), Personal Information Management - PIM 2016, Personal information management workshop

[13] Redwine, G. (2015), Personal Digital Archiving, Digital Preservation Coalition, Retired on $23^{\text {rd }}$ April 2018, from:https://www.dpconline.org/docs/technology-watch-reports/1460-twr15-01/file

[14] Sandusky, J. (2017), How Recordkeeping Ensures Trust in Digital Archives Robert, Information Science and Technology, USA.

[15] Sinn, D., Syn, S. Y. \& Kim, S. (2011), Personal records on the web: Who's in charge of archiving, Hotmail or archivists?, Library \& Information Science Research, pp. 320- 330

[16] Sun, S. \& Belkin, J. B. (2016), Managing Personal Information over the Long-term, Or Not? Experiences by Type 1 Diabetes Patients, Retrieved $26^{\text {th }}$, April 2018, from

[17] http://sci-hub.tw/https://onlinelibrary.wiley.com/doi/10.1002/pra2.2016.14505301070 